\title{
Tingkat Adversity Quotient Matematis pada Mahasiswa Program Studi Tadris Matematika IAIN Curup
}

\author{
Anisya Septiana \\ Institut Agama Islam Negeri (IAIN) Curup \\ anisya.septiana@ymail.com
}

\begin{tabular}{l}
\hline \hline Article Info \\
\hline Article history: \\
Received April $22^{\text {th }}, 2019$ \\
Revised April $30^{\text {th }}, 2019$ \\
Accepted May $1^{\text {st }}, 2019$
\end{tabular}

Keywords:

Adversity Quotient (AQ);

Students

\section{Abstract}

The purpose of this study was to determine the level of Adversity Quotient (AQ) students Tadris of the Mathematics Program of IAIN Curup. AQ is a person's ability to face the difficulties. Student difficulties faced can be in the form of assignments given by the lecturer, doing exams, and others. AQ level is categorized into three, namely quitter, camper, and climber. The subjects of this study were 33 students consisting of semesters II and IV. The research method used is a qualitative descriptive method. The process of collecting data is using a questionnaire. Data analysis using Microsoft Excel help. AQ score can be used as a reference for how a student responds to the difficulties faced. Based on the research that has been done, it is known that the $A Q$ criteria that dominate are the camper categories as many as 27 (81.82\%). Campers are a category of students who have tried, but the work that has been completed is not necessarily good. They are quite satisfied with what has been obtained, but their potential is not maximized. Therefore, they must be encouraged to improve their performance or efforts to be more maximal and more active and never give up in the face of difficulties.

\section{Kata Kunci:}

Adversity Quotient (AQ); Mahasiswa
Tujuan dari penelitian ini adalah untuk mengetahui tingkat Adversity Quotient (AQ) mahasiswa Program Studi Tadris Matematika IAIN Curup. AQ adalah kemampuan seseorang dalam menghadapi kesulitan yang dihadapi. Kesulitan yang dihadapi mahasiswa dapat berupa tugas yang diberikan dosen, mengerjakan ujian, 
52 | Septiana: Tingkat Adversity Quotient Matematis pada Mahasiswa Program Studi ...

dan lainnya. Level AQ dikategorikan menjadi tiga, yaitu quitter, camper, dan climber. Subyek penelitian ini adalah 33 mahasiswa yang terdiri dari semester II dan IV. Jenis Penelitian ini adalah deskriptif kualitatif. Pengumpulan data dilakukan dengan angket. Analisis data menggunakan bantuan microsoft excel. Skor AQ dapat digunakan sebagai acuan bagaimana seorang mahasiswa merespon kesulitan yang dihadapi. Hasil penelitian yang diperoleh dari kriteria AQ yang mendominasi adalah kategori camper yaitu sebanyak 27 $(81,82 \%)$. Camper adalah kategori mahasiswa yang telah berusaha, tetapi pekerjaan yang telah diselesaikan belum tentu baik. Mereka sudah cukup puas dengan apa yang telah diperoleh, tetapi potensi mereka tidak teraktualisasi secara maksimal. Oleh karena itu, mereka harus didorong untuk meningkatkan kinerja atau usaha mereka agar lebih maksimal dan lebih giat serta pantang menyerah dalam menghadapi kesulitan.

\section{PENDAHULUAN}

Manusia pada dasarnya selalu menghadapi masalah, baik masalah yang memiliki penyelesaian yang sederhana hingga penyelesaian yang kompleks. Salah satu sumber masalah yang dihadapi tidak terlepas dari tuntutan perubahan era globalisasi dan perkembangan IPTEK yang sudah sangat pesat dan tidak dapat ditawar lagi. Tetapi, tujuan perubahan dan perkembangan tersebut adalah untuk kehidupan manusia yang lebih baik.

Pada era digital ini, mahasiswa sebagai generasi penerus bangsa dan sebagai agen of change harus mampu bersaing secara global yang memerlukan pemikiran kreatif, kritis, logis, dan sistematis, agar dapat menghadapi tantangan yang besar dan menunjukkan inovasi untuk perkembangan dunia demi tercapainya kesuksesan. Mayoritas masyarakat berpendapat Intelligence Quotient (IQ) merupakan penentu kesuksesan belajar dan hidup seseorang (Suparno, 2004). Pendapat tersebut ternyata bergeser ke pendapat bahwa Emotional Quotient (EQ) juga mempengaruhi keberhasilan seseorang (Goleman, 2000). Dalam suatu hasil penelitian menunjukkan adanya suatu indeks dalam mencapai kesuksesan selain tingkat IQ dan EQ, yaitu Adversity Quotient (AQ). AQ 
merupakan indeks yang lebih baik dalam mencapai kesuksesan daripada IQ ataupun keterampilan bahkan sosial (Cando \& Villacastin, 2014). AQ suatu kecerdasan ketahanmalangan (Candisa, 2006), AQ merupakan potensi kegigihan (Subiyanto, 2006), AQ yaitu kehandalan mental (Laksomono, 2006), dan AQ sebagai kecerdasan ketangguhan (Efendi, 2005).

AQ dikonseptualisasikan sebagai daya tahan atau ketangguhan dalam menghadapi masalah. AQ dapat dipandang sebagai kecerdasan ketegaran atau daya juang (Stoltz, 2007). Kesuksesan dapat diartikan sebagai level dimana seseorang maju bergerak terus ke depan dalam menjalani kehidupannya, walaupun terdapat banyak hambatan. Ibarat ketika seseorang mendaki gunung yang curam dan tak kenal lelah untuk menuju sampai ke puncak. Selain itu, AQ juga merupakan tolak ukur untuk mengetahui respon seseorang dalam menghadapi kesulitan dan serangkaian alat yang dapat memperbaiki efektivitas diri serta profesionalisme diri.

Dalam kajian psikologi, AQ didefinisikan sebagai kemampuan seseorang untuk mengelola kesulitan yang dihadapi setiap hari (Cornista \& Macasaet, 2013). Bagi seseorang yang memiliki kemampuan dalam menghadapi tantangan, maka seseorang tersebut dapat merespon atau menyelesaikan segala sesuatu dari masalah yang dihadapi sehari-hari. Beradaptasi secara baik terhadap kesulitan dapat terjadi karena AQ melatih kemampuan alami untuk belajar menghadapi kesulitan (Devakumar, 2012). Setiap mahasiswa mempunyai kepribadian yang berbeda, memiliki keunikan tersendiri, oleh sebab itu kemampuan mahasiswa akan berbeda-beda dalam menghadapi kesulitan. Maka disinilah peran indeks AQ dalam kegiatan proses berfikir mahasiswa pada saat proses perkuliahan.

Mahasiswa Program Studi Tadris Matematika Institut Agama Islam Negeri (IAIN) Curup selama proses perkuliahan di kelas bisa dideteksi bagaimana mereka menghadapi materi dan soal-soal yang non rutin atau soal yang dianggap sebagai soal yang rumit yang pada dasarnya ketika mereka berada di tingkat sekolah menengah belum memperoleh materi- 
54 | Septiana: Tingkat Adversity Quotient Matematis pada Mahasiswa Program Studi ...

materi perkuliahan yang bersifat analitis dan terapan, walaupun materi dasar telah dikenal sebelumnya. Seperti mata kuliah Aljabar Linier, Program Liner, Metode Analitik, dan sebagainya. Matematika mempunyai sifat khas kalau dibandingkan dengan disiplin ilmu yang lain. Matematika berkaitan dengan ide abstrak yang diberi simbol yang tersusun secara hierarkis dan penalarannya deduktif (Sudarman, 2012). Oleh sebab itu, proses pembelajaran matematika seharusnya tidak disamakan begitu saja dengan ilmu yang lain. Belajar matematika adalah aktivitas mental tingkat tinggi yang menuntut pemahaman dan ketekunan berlatih. Dengan demikian, pada saat belajar matematika sudah pasti menemukan kesulitan. Padahal belajar pada dasarnya adalah mengatasi kesulitan. Mengalami kesulitan, berarti seseorang masih diberi kesempatan untuk mengasah kembali kepekaan perasaan, ketajaman pikiran, dan kecerdasan (Ronnie, 2006).

Beberapa hal yang telah diamati ketika mahasiswa diminta untuk menyelesaikan soal-soal yang diberikan adalah ada sebagian dari mahasiswa langsung mengeluh ketika baru membaca soal, ada juga yang hanya terdiam tanpa mau berusaha menyelesaikannya, ada juga yang berusaha menyelesaikan walaupun belum tepat, dan ada juga mahasiswa yang menyelesaikan dengan penuh percaya diri dengan penuh rasa pantang menyerah. Atau mudah dipahami misalkan ada dua orang mahasiswa yang diberikan tugas yang sama. Kedua mahasiswa memberikan tanggapan yang berbeda terhadap tugas yang diberikan. Misalkan pada mahasiswa pertama memberi respon bahwa mahasiswa tersebut tidak mampu untuk menyelesaikan tugas yang diberikan dengan baik dan pada akhirnya menyerah, mahasiswa tersebut beranggapan mereka tidak mungkin dapat diselesaikan karena keterbatasan yang dimilikinya. Sedangkan mahasiswa kedua menyadari akan kelemahannya, tetapi ia tetap berusaha untuk menyelesaikannya. Sebagai mahasiswa di bawah naungan kampus yang islami sudah selayaknya mereka meyakini bahwa sesungguhnya sesudah kesulitan itu ada kemudahan. Seperti yang telah dijanjikan Allah bahwa di balik kesulitan, pasti ada jalan keluar yang begitu dekat, dalam surat Al-Insyirah: 5-6. 
Di saat proses berfikir seringkali mahasiswa menghadapi kesulitan, jika dikaitkan dengan tingkat $\mathrm{AQ}$ yang dimiliki oleh mahasiswa, dimungkinkan mahasiswa dengan level AQ yang berbeda diyakini juga akan berbeda di dalam proses berfikirnya. Hal ini disebabkan AQ yang dimiliki seseorang mahasiswa akan menunjukkan kemampuan mahasiswa tersebut dalam menghadapi kesulitan yang dihadapi. Menurut (Stoltz, 2007) ada tiga pembagian kategori AQ dalam mengelompokkan seseorang berdasarkan tingkat kemampuan mengatasi masalah, yaitu quitter (level rendah), camper (level sedang), dan climber (level tinggi). Seperti layaknya seorang pendaki gunung, orang yang memiliki AQ level tinggi, tidak akan pantang menyerah atau tidak akan takut dalam menghadapi berbagai liku dan terjalnya dalam proses pendakian. Bahkan mereka akan memiliki pandangan dalam mengubah tantangan menjadi peluang. Karena pada hakikatnya manusia harus memiliki filosofi pendakian, yaitu bergerak maju mencapai tujuan hidup ke depan. Atau bisa dicontohkan seorang mahasiswa dalam menyelesaikan studi mengejar sarjana yang mampu berkompeten.

Quitter merupakan kategori sekelompok orang yang kurang memiliki rasa kemauan untuk menerima tantangan yang diberikan, mudah berputus asa dan mudah menyerah, atau juga bisa berhenti di awal saat adanya tantangan. Mereka lebih memilih jalan yang lebih mudah dan lurus saja. Tidak berani mengambil resiko dan memiliki motivasi yang rendah dalam belajar. Camper, sekelompok yang lebih baik dari quitter. Pada kelompok ini, sudah memiliki kemauan untuk berusaha, tetapi mereka berhenti karena mereka sudah tidak mampu lagi. Banyak potensi mereka yang tidak teraktualisasikan karena mereka tidak lagi fokus dalam menyelesaikan tantangan. Mereka puas dengan apa yang telah mereka kerjakan, namun seringkali mereka tidak menyelesaikan tugas yang diberikan dengan baik. Sedangkan climber adalah mereka yang memiliki rasa keberanian menghadapi resiko dan menyelesaikan tugas yang diberikan secara tuntas. Mereka menikmati dan bertahan terhadap tantangan atau kesulitan yang dihadapi. Pada umumnya, para climber akan mendapat kesuksesan dan keberhasilan. 
56 | Septiana: Tingkat Adversity Quotient Matematis pada Mahasiswa Program Studi ...

AQ menjadi prediktor keberhasilan seseorang seperti yang diungkapkan (Jean \& Luni N, 2014), "AQ as a predictor of success, is highly useful in allowing an individual to determine how he/she would manage in the face of an adversity. However, overall $A Q$ does not pinpoint weak areas that would need improvement". Untuk memprediksi AQ seseorang, maka ada empat dimensi dasar yang dijadikan instrumen AQ (Stoltz, 2007), yaitu control/C (kendali) berkaitan dengan seberapa besar orang mampu mengendalikan kesulitan yang dihadapi. Semakin tinggi tingkat kendali seseorang, maka seeorang akan semakin bertahan menghadapi masalah dan sebaliknya. Origin and ownership/O $\mathrm{O}_{2}$ (kepemilikan) merupakan pengakuan terhadap siapa dan apa yang menyebabkan masalah atau kesulitan. Orang yang memiliki $\mathrm{O}_{2}$ yang rendah akan menganggap kesulitan yang datang adalah kesalahan, kebodohan, ataupun kecerobohan diri mereka sendiri. Reach $/ R$ (jangkauan), sejauh mana kesulitan akan menjangkau bagian yang lain. Semakin tinggi jangkauan seseorang, maka akan semakin besar kemungkinan mereka merespon kesulitan dalam bagian yang lain. Yang terakhir adalah Endurance/E ( daya tahan). Dimensi ini berkaitan dengan pandangan seseorang akan lama atau tidaknya kesulitan yang berlangsung. Seseorang yang memiliki daya tahan yang tinggi akan memiliki harapan dan sikap optimis terhadap tantangan atau kesulitan. Keempat dimensi ini dikenal dengan singkatan $\mathrm{CO}_{2} \mathrm{RE}$.

Untuk membantu dosen dalam melatih kemampuan mahasiswa mengatasi kesulitan-kesulitan yang dihadapi selama proses perkuliahan, maka diperlukan pengetahuan tentang bagaimana tingkat AQ mahasiswa Prodi Tadris Matematika IAIN Curup menggunakan Adversity Response Profile (ARP) yang diadaptasi dari ARP yang telah dikembangkan oleh Stoltz.

\section{METODE PENELITIAN}

Metode penelitian ini adalah metode deskriptif kualitatif. Penelitian kualitatif tidak melakukan generalisasi tetapi lebih menekankan kedalaman informasi (Sugiyono, 2018). Penelitian deskriptif bertujuan 
untuk mendeskripsikan atau menggambarkan obyek yang diamati apa adanya. Tujuan dari penelitian ini adalah untuk mengetahui tingkat AQ mahasiswa Prodi Tadris Matematika dan mengelompokkan pada kategori quitter, camper, atau climber. Subyek penelitian ini adalah mahasiswa tadris matematika semester II dan IV dengan jumlah 33 orang.

Instrumen penelitian yang digunakan adalah lembar angket AQ (Adversity Responses Profile/ARP) yang diadaptasi dari (Stoltz, 2007). Angket atau kuisioner merupakan teknik pengumpulan data yang efisien bila peneliti tahu dengan pasti variabel yang akan diukur dan tahu apa yang diharapkan dari responden (Sugiyono, 2018). Angket berisi itemitem pernyataan yang disusun berdasarkan dimensi $\mathrm{CO}_{2} \mathrm{RE}$. Selanjutnya angket disebarkan kepada mahasiswa tadris matematika semester II dan IV.

Proses analisis data menggunakan bantuan microsoft excel dan hasil skor angket AQ disederhanakan berupa kategori quitter, camper, atau climber. Tujuan pengelompokkan ini ialah untuk menempatkan individu dalam posisi yang berjenjang menurut suatu rangkaian berdasarkan atribut yang diukur (Azwar, 2015). Pengkategorian tersebut adalah dengan melihat skor yang diperoleh mahasiswa.

\begin{tabular}{cc} 
Tabel 1. Kategori Tingkat & Adversity \\
\hline Interval Skor & Kategori AQ \\
$X<93$ & Quitter \\
$93 \leq X<147$ & Camper \\
$147 \leq X$ & Climber \\
\hline
\end{tabular}

\section{HASIL PENELITIAN DAN PEMBAHASAN}

Untuk mengetahui tingkat AQ mahasiswa diberikan angket ARP yang telah disusun sebelumnya. Angket AQ yang diberikan kepada 33 mahasiswa Prodi Tadris Matematika yang berisi 40 item pernyataan. Pengisian angket dilakukan di ruang kelas. Sebelum pengisian angket, terlebih dahulu dijelaskan tentang petunjuk angket AQ dan mahasiswa 
58 | Septiana: Tingkat Adversity Quotient Matematis pada Mahasiswa Program Studi ...

juga dihimbau untuk mengisi angket dengan jujur. Data angket yang telah diperoleh kemudian diolah menggunakan bantuan microsoft excel. berdasarkan hasil angket $\mathrm{AQ}$, diperoleh skor yang selanjutnya skor tersebut dikategorikan berdasarkan 3 kelompok. Interpretasi skor tingkat AQ dapat dilakukan secara langsung dengan cara menskoring respon mahasiswa. Berikut data angket AQ yang telah diperoleh dari mahasiswa.

Tabel 2. Analisis Data Angket Tingkat Adversity Quotient Mahasiswa

\begin{tabular}{cccc} 
Interval Skor & Kategori AQ & Frekuensi & Persentase \\
\hline$X<93$ & Quitter & - & - \\
$93 \leq X<147$ & Camper & 27 & $81,82 \%$ \\
$147 \leq X$ & Climber & 6 & $18,18 \%$ \\
Jumlah & & 33 & $100 \%$ \\
\hline
\end{tabular}

Hasil analisis data yang telah dilakukan menunjukkan bahwa dari 33 mahasiswa tadris matematika yang menjadi sampel, sebanyak $0(0 \%)$ mahasiswa berada pada kategori quitter, 27 (81,82\%) mahasiswa berada pada kategori camper, dan $6(18,18 \%)$ mahasiswa berada pada kategori climber. Dengan demikian, sebagian mahasiswa ada pada kategori camper.

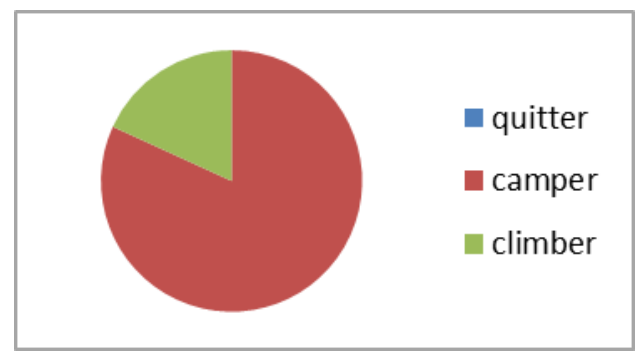

\section{Diagram 1. Kategori Mahasiswa Berdasarkan AQ}

Berdasarkan teori AQ, mahasiswa yang tergolong kategori camper pada umumnya merasa puas terhadap apa yang telah mereka gapai walaupun belum maksimal. Mahasiswa cepat merasa puas atas apa yang 
kemudian diusahakan, walaupun meski harus masih ditingkatkan. Disinilah peran dosen, khususnya dosen yang mengajar mata kuliah keprodian untuk lebih memotivasi mahasiswa dalam menyelesaikan tugas ataupun soal-soal yang dianggap sulit agar memperoleh hasil yang maksimal.

Meskipun harus selalu berlatih agar terbiasa dengan soal-soal yang bersifat non rutin. Sehingga menyelesaikan soal ataupun tugas mata kuliah keprodian matematika bukanlah sesuatu yang sulit. Oleh sebab itu, setiap mahasiswa dapat mengerjakannya, walaupun memiliki tingkat daya tahan yang berbeda-beda dalam menghadapi kesulitan. Diharapkan mahasiswa mampu mengubah tantangan menjadi suatu peluang. Sebagaimana dijelaskan di atas, bahwa tingkat daya tahan atau daya juang mahasiswa dalam menghadapi kesulitan dapat diukur dan dideteksi dengan Adversity Responses Profile (ARP).

\section{SIMPULAN}

Hasil penelitian dan pembahasan yang telah dijabarkan diperoleh kesimpulan yaitu dari 33 mahasiswa Prodi Tadris Matematika IAIN Curup sebanyak $0(0 \%)$ mahasiswa berada pada kategori quitter, 27 $(81,82 \%)$ mahasiswa berada pada kategori camper, dan $6(18,18 \%)$ mahasiswa berada pada kategori climber. Dengan demikian, sebagian mahasiswa ada pada kategori camper, sebagaimana telah dijelaskan bahwa camper adalah kategori mahasiswa yang telah berusaha, tetapi pekerjaan yang telah diselesaikan belum tentu baik. Mereka sudah cukup puas dengan apa yang telah diperoleh, tetapi potensi mereka tidak teraktualisasi secara maksimal. Oleh karena itu, mereka harus didorong untuk meningkatkan kinerja atau usaha mereka agar lebih maksimal dan lebih giat serta pantang menyerah dalam menghadapi kesulitan.

\section{DAFTAR PUSTAKA}

Azwar, S. (2015). Penyusunan Skala Psikologi. Yogyakarta: Pustaka Pelajar 
60 | Septiana: Tingkat Adversity Quotient Matematis pada Mahasiswa Program Studi ...

Candisa, I. (2006). Mengajar Siswa yang Beragam dengan Aneka Cara. Retrieved from http://www. balipost.co.id

Cando, J. M., \& Villacastin, L. (2014). The Relationship Between Adversity Quotient (AQ) and Emotional Quotient (EQ) and Teaching Performance of Collage PE Faculty Members of CIT. International Journal of Scsiences: Basic and Apllied Research (IJSBAR) , 354-367

Cornista, G. A., \& Macasaet, C. J. (2013). Adversity Quotient and Achievement Motivation of Selected Third Year and Fourth Year Psychology Student of De La Salle. De La Salle Lipa: The Faculty of the College of Education, Arts, and Sciences

Devakumar, M. (2012). Study of the Adversity Quotient of Secondary Quotient in Relation to Academic Self Concept and Chievement Motivation. Mumbai: University of Mumbai

Efendi, A. (2005). Revolusi Kecerdasan Abad 21: Kritik MI, EI, SQ, AQ, dan Successful Intelligence Atas IQ. Bandung: Alfabeta

Goleman, D. (2000). Emotional Intellegence (Kecerdasan Emosional). Jakarta: PT. Gramedia Pustaka Utama

Jean, M. D., \& Luni N, V. (2014). The Relationship Between Adversity Quotient (AQ) and Emotional Quotient (EQ) and Teaching Performance of Collage PE Faculty Members of CIT University. International Journal of Science : Basic and Apllied Research (IJSBAR) 18 , 354-467. Retrieved from http://gssrr.org/index.php? journal=JournalOfBasicAndApplied\&page $=$ article\&op=download $\&$ path $\% 5 \mathrm{~B} \% 5 \mathrm{D}=3111 \&$ path $\% 5 \mathrm{~B} \% 5 \mathrm{D}=2031$

Laksomono, H. (2006). Jiwa "Climber" Pengusaha. Dipetik Februari 22, 2019, dari http://www. paramuslim.com

Ronnie, M. (2006). The Power of Emotional \&Adversity Quotient for Teacher. Jakarta: Hikmah (PT Mizan Publika)

Stoltz, P. G. (2007). Adversity Quotient: Mengubah Hambatan Menjadi Peluang. Jakarta: PT Grasindo

Subiyanto, P. (2006). Biarkan Anak Belajar Memilih. Dipetik Februari 22, 2019, dari http://www.bali-travelnews.com 
Sudarman. (2012). Adversity Quotient: Kajian Kemungkinan Pengintegrasiannya dalam Pembelajaran Matematika. AKSIOMA, 55-62. Retrieved from https://journal.unnes.ac.id/sju/index.php/ ujmer/article/download/ 12908/7044/

Sugiyono. (2018). Metode Penelitian. Bandung: Alfabeta

Suparno, P. (2004). Teori Intelegensi Ganda dan Aplikasinya di Sekolah. Yogyakarta: Kanisius (Anggota Ikapi) 
62 | Septiana: Tingkat Adversity Quotient Matematis pada Mahasiswa Program Studi ... 